\title{
ALCOOLGELSON, COVIDSON E CORONALDA: PRENOMES DE PESSOAS EM TEMPOS DE PANDEMIA NO BRASIL
}

\section{ALCOOLGELSON, COVIDSON E CORONALDA: FIRST NAMES IN PANDEMIC TIME}

\section{Juliana Soledade ${ }^{1}$ Universidade de Brasília/Universidade Federal da Bahia/CNPq}

Resumo: Este artigo se dedica ao estudo da antroponímia brasileira, em especial, às projeções sobre os possíveis nomes de pessoas no suposto cenário pós-pandemia. Com base em dados coletados nas mídias sociais, buscamos analisar os prenomes inovadores a partir da perspectiva da morfologia construcional. Os resultados corroboram as evidências de que os nomes inovadores no Brasil são essencialmente biformativos e seguem padrões esquemáticos já previstos no sistema antroponímico do português brasileiro.

Palavras-chave: Antroponímia; Inovação; Morfologia Construcional; Pandemia; Tabu Linguístico

Abstract: This article is dedicated to the study of Brazilian anthropony, in particular, the projections about the possible names o fpeople in the post-pandemic scenario. Basedon data collectedon social media, we seek to analyze innovative first names from the perspective of constructional morphology. The results corroborate the evidence that innovative names in Brazil are essentially biformative and follow schematic patterns already predicted in the anthroponomic system of Brazilian Portuguese.

Keyword: Anthroponymy; Innovation; Constructional Morphology; Pandemic, Linguistic Taboo

${ }^{1}$ Endereço eletrônico: julisoledade@gmail.com 


\section{INTRODUÇÃO}

O léxico é, naturalmente, uma classe aberta dentro do sistema linguístico das línguas naturais e as inovações ou neologismos cumprem a função de dar nome a novos objetos, novas tecnologias, novas ideias, novos comportamentos, em uma sociedade em constante transformação. A vivência de uma pandemia é um marco de transformação para todos os seres humanos vivos neste momento. No ano de 2020, a humanidade sofreu uma grande ruptura nos padrões de interação social vigentes, o que tornou necessário o uso de um léxico inovador, seja no sentido de passarmos a conhecer nomes científicos como SarsCoV-19, Corona Vírus, Cloroquina, aerossóis, assintomático, comorbidade, seja no sentido de absorvermos nomes estrangeiros, como lockdown e live, seja no sentido de expandirmos e ressignificarmos nomes que já conhecíamos, mas que, no contexto atual, assumiram novas feições, como álcool em gel, confinamento, contágio, epidemia, máscara, pandemia, quarentena, vírus, entre outros.

De acordo com Cartier (2018), os nomes próprios constituem a categoria mais aberta de todas as categorias do léxico. Segundo dados do IBGE, tendo como referência o censo de 2010, existem cerca de $130 \mathrm{mil}^{2}$ nomes diferentes registrados no Brasil. Acreditamos, com base nas estimativas que temos feito para a elaboração do Dicionário de nomes do Brasil ${ }^{3}$, que o número de nomes inovadores (ainda não registrados nos dicionários onomásticos) cheguem a 50 mil, cerca de $40 \%$ do total dos nomes computados pelo IBGE, sendo muitos deles registrados pela primeira vez no Brasil em 1940 e em 1950. Assim, consideramos que, no português brasileiro, o léxico antroponímico se apresenta particularmente aberto às inovações, em especial, a partir do século XX, mais especificamente, a partir do seu segundo quartel, em face de fatores sócio-históricos já explorados por Soledade, Rodrigues e Lopes (2019).

\footnotetext{
2 Estão incluídas, nesse número, as variantes gráficas de um mesmo nome.

${ }^{3}$ Disponível em: https://dicionariodenomesdobrasil.com.br/ Acesso em: 23 out. 2020
} 
Assim, considerando tanto a abertura do sistema antroponímico brasileiro às inovações e a possibilidade de as inovações serem motivadas por fatores de ordem sociocultural, seria muito natural compreendermos possíveis impactos do sistema de nomeação de pessoas advindos da vivência desse momento singular que é o da pandemia de covid-19.

A partir de março de 2020, viralizaram nas mídias sociais postagens e vídeos de humor que fazem projeções para os nomes das crianças daqui a 10 ou 30 anos, em face da influência que a pandemia poderia ter na nomeação dos brasileiros. É justamente sobre esses dados que nos debruçaremos neste artigo. O corpus é constituído de 38 prenomes inovadores relacionados à pandemia que estão presentes em postagens em redes sociais e em vídeos do YouTube que apresentam essa temática.

Cabe ressaltar que, embora já tenhamos notícias de registros de crianças com nomes relacionados à pandemia em outras partes do mundo, no Brasil esse fenômeno ainda não foi divulgado pela mídia, então, ainda não sabemos se essa já é uma realidade.

Este artigo é, pois, constituído de duas partes. Na primeira nos dedicamos a explicar a forma como entendemos os processos de inovação na antroponímia brasileira do ponto de vista da morfologia construcional apresentando o mapeamento dos fenômenos até aqui identificados em nossas pesquisas e, na segunda, analisamos os dados coletados em face dessa perspectiva teórica, buscando evidenciar como se dá a análise a partir do olhar do falante/receptor, através de uma pesquisa com 100 informantes e como se dá a análise do ponto de vista do falante/emissor, em termos construcionais. Por fim, apresentamos algumas considerações finais acerca do aspecto projecional do uso dessas inovações antroponímicas, considerando que acionam o frame PANDEMIA. 


\section{ANTROPONÍMIA, INOVAÇÃO E CONSTRUÇÕES}

Os antropônimos são elementos linguísticos de máxima relevância para compreendemos a história de uma comunidade de fala. Concordamos com Dick, quando diz que o nome próprio tem o papel de "registrar atitudes e posturas sociais de um povo, suas crenças, profissões, região de origem, entre outros aspectos" (DICK, 2007, p. 2).

No caso da antroponímia brasileira, o aspecto singular de sua intensa abertura à inovação, a priori, revela que o povo brasileiro possui menor apego a cânones e tradições, sobretudo se comparado a outras culturas, nas quais o rol de prenomes em uso fica circunscrito a listas de nomes permitidos ou interditos.

As inovações na antroponímia decorrem de múltiplas motivações, sendo a principal delas a homenagem a familiares ${ }^{4}$. Mas aspectos da vivência em sociedade também incidem sobre as motivações para a criação de nomes de pessoas. Por exemplo, em 2011, um casal paulista registrou seu filho com o nome de Facebookson, motivado pelo fato de terem se conhecido através da rede social. Eventos historicamente datados são também motivadores de prenomes, por exemplo, em 1930 a Argentina sofreu um Golpe de Estado, também identificado como Revolução de Setembro, que suspendeu a Constituição e submeteu o governo do país a uma junta militar. Existem, no Brasil, 2.937 pessoas registradas com o prenome Argentina, surpreendentemente, a maior parte desses registros (840) se concentra na década de 1930 como demonstra o gráfico a seguir:

\footnotetext{
${ }^{4}$ Estão em curso dois estudos acerca das motivações para atribuição de nomes no Brasil, tratase de Soledade e Coutinho (2020, no prelo) e Soledade (2020, no prelo). Nesses trabalhos, em que são analisados 3.181 dados de informações sobre motivação para atribuição de prenomes, há indicação de que a categoria predominante em termos de motivação é a relacionada a homenagens (a familiares, personalidades da mídia, do esporte, a amigos, brinquedos e lugares), sendo que, dentre essas, é a homenagem a familiares que prevalece.
} 
Figura 1- Dados de registros de pessoas com o prenome Argentina



Fonte: https://censo2010.ibge.gov.br/nomes/\#/search/response/183, acesso em: 20 out. 2020

Em 1969, divulgou-se a chegada do homem à lua e o principal personagem desse evento foi o astronauta Neil Armstrong. Na década de 1970, 85 pessoas são registradas, pela primeira vez, no Brasil, com o prenome de Armstrong. Como se pode ver no gráfico a seguir, esse foi o momento de ápice de popularidade do nome no país:

Figura 2- Dados de registros de pessoas com o prenome Armstrong

\begin{tabular}{|l|l|l|l|l|l|l|l|l|}
\hline Armstrong & Ambos os sexos \\
\hline Brasil & Municipio \\
\hline
\end{tabular}

Pesquisar

Sumário

\begin{tabular}{|c|c|}
\hline Frequência: & 150 pessoas \\
\hline \% Percentual: & $0,00 \%$ \\
\hline - Popularidade: & $31.877^{\circ}$ \\
\hline \multicolumn{2}{|c|}{ i Saiba mais sobre as Cidades } \\
\hline \multicolumn{2}{|c|}{$\star$ Maior taxa por 100.000 pessoas } \\
\hline UF & Minas Gerais \\
\hline Taxa & 0,13 \\
\hline \multicolumn{2}{|c|}{$\&$ Compartilhe Armstrong via } \\
\hline f Facebook & \\
\hline
\end{tabular}

Nascimentos por década

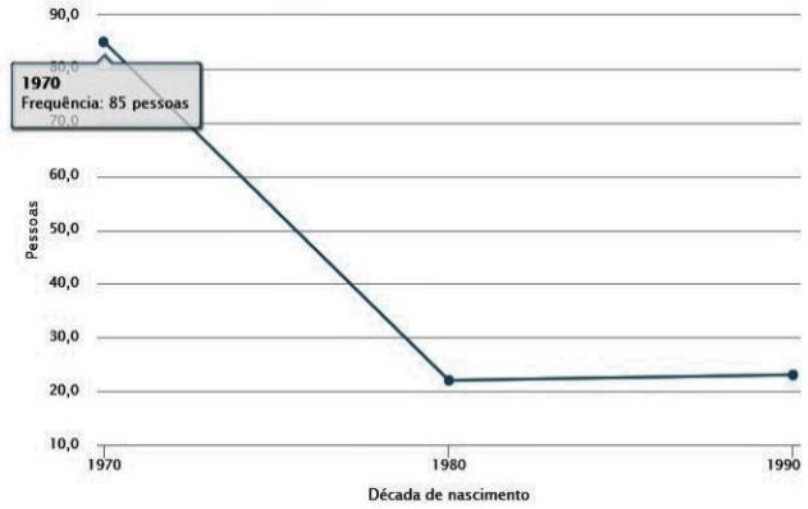

Fonte: https://censo2010.ibge.gov.br/nomes/\#/search/response/80, acesso em: 20 out. 2020 
Assim, do ponto de vista sócio-histórico e cultural, a possibilidade de inovação antroponímica decorrente do contexto da pandemia é algo que naturalmente pode ser pautado, como bem demonstra o volume de informações que aparecem nas mídias sociais sobre possíveis construções antroponímicas inovadoras, tendo por base elementos do léxico que são acionados pelo frame pandemia.

Cada nome inovador no Brasil carrega em si uma história própria e particular. Em verdade, podem se tratar, até mesmo, de variadas histórias e percursos de construção, por exemplo, temos conhecimento de duas pessoas chamadas Maricleide, no entanto, a primeira tem seu nome originado do cruzamento vocabular entre os nomes dos pais Mário e Cleide, enquanto o nome da segunda se origina do cruzamento do nome da mãe com o nome da irmã Maria e Cleide, respectivamente. Assim, embora tenhamos como constructo um mesmo prenome e um mesmo processo gerador (cruzamento vocabular), a história da sua criação remete a percursos distintos, tomando por base diferentes prenomes: Maria, Mário e Cleide.

A par dessa realidade, olhando a língua e o sistema antroponímico a partir de uma visão mais holística, é possível perceber padrões formativos recorrentes, que dão à nossa antroponímia um caráter mais dinâmico, uma vez que o nosso arcabouço de itens lexicais a serviço da nomeação (prenomes, essencialmente) não se limita ao uso de formações herdadas.

Nesse sentido, é preciso que compreendamos que o sistema lexical antroponímico, tal qual o sistema lexical comum, não se organiza apenas em torno de listas de formas herdadas e armazenadas na memória dos falantes, mas também em torno de redes, hierarquicamente organizadas, de padrões e esquemas construcionais que permitem a criação de novas unidades, tomando como base o que denominamos formativos antroponímicos.

Nos estudos da antroponímia no Brasil, deparamo-nos com uma infinidade de prenomes de caráter inovador e, ao estudá-los, pudemos perceber 
que os padrões construcionais são reforçados por construções que levam em conta elementos formativos recorrentes. Partindo do pressuposto de que esquemas construcionais são adquiridos através de generalizações sobre instanciações plenamente especificadas, com base em Booij (2010, 2012, 2017), depreendemos, em relação aos antropônimos, que, por exemplo, após a incorporação ao acervo lexical de nomes tradicionais como Adalberto, Alberto, Roberto, os falantes do português brasileiro teriam generalizado o seguinte esquema:

$\left[\left[\mathrm{X}_{\mathrm{FA}}-\text { bertofa }\right]\right]_{\mathrm{NP}} \leftrightarrow[$ nome de pessoa do sexo masculino $\left.]\right]_{\mathrm{NP}^{5}}$

A partir desse esquema são instanciados prenomes como Adilberto, Alciberto, Edelberto, Elisberto, Francisberto, Juberto, Loriberto, Vanberto, entre outros.

Em trabalhos anteriores (SOLEDADE, 2018, 2019, 2020), conseguimos mapear os principais processos construcionais concatenativos e não concatenativos que permitem a criação de novos prenomes no Brasil. Em resumo, identificamos nove principais processos, que sintetizamos a seguir.

O primeiro diz respeito à transposição de nomes do léxico comum para o léxico antroponímico: Brisa (1.903 f.), Flor (2.640 f.), Jade (11.297 f.), Júpiter (68 m.), (Lua 840 f.), Luz (1.462 f)/ Luz (1.315 m.), Mar (163 f.)/ Mar (90 m.), Margarida (114.690 f.), Mel (4.047 f.), Pérola (3.861 f.), Sol (380f.)/ Sol (147 m.).

Também é possível encontrar variados casos em que um nome tradicional é levemente alterado em sua configuração gráfico-fônica, a fim de gerar um nome inovador, até agora, os nossos dados revelam que, nesse fenômeno, predominam alterações entre os fonemas $[\mathrm{b}] \sim[\mathrm{d}] \mathrm{e}[\mathrm{d}] \sim[\mathrm{t}]$, mas não exclusivamente: Cívia (23 f. - Lívia), Dalbino (35 m. - Balbino), Deatriz (26 f. - Beatriz), Dejamim (22 m. Bejamin), Derenice (337 f. - Berenice), Fâmela (60 f. - Pâmela), Ingrite (152 f. - Indrid), Talila (282 f. - Dalila), Tanilo (97 m. - Danilo), Tiego (1.287 m. - Diego).

${ }^{5}$ As siglas usadas nesses esquemas correspondem a: FA - formativo antroponímico e NP nome próprio. 
Outro fenômeno gerador de novos antropônimos no Brasil é a hipocorização, processo em que se reduz o nome por perda fônica (aféreses, síncopes e apócopes) ou, ainda, por reduplicação de sílabas tônicas ou átonas do nome. De acordo com Gonçalves (2006, p. 8), “[...] antropônimos são encurtados afetivamente, resultando numa forma diminuta que mantém identidade com o prenome ou com o sobrenome original", Por exemplo: Cacá (41 m.), Cau (74 m.), Dedé (487 m.), Ed (3.275 m.), Fafá (26f.), Juli (3.556 f.), Mari (25.678f.), Nina (8.267 f.), Zé (12.617 m.), Zezé (203f.)/ Zezé (179 m.).

Em relação aos outros processos que servem para a construção de nomes próprios no Brasil, destacamos a hipótese de que, em sua maioria, eles se utilizam de uma estrutura biformativa. Assim, excetuando-se a transcategorização, as alterações gráfico-fônicas e a hipocorização, nos demais processos, sejam de natureza compositiva, sejam de natureza afixativa, ou não-concatenativa, predominam os nomes construídos pela junção de dois elementos (formativos ou itens lexicais) que podem ser tanto provenientes do léxico onomástico pessoal quanto do léxico comum. Listaremos alguns exemplos categorizados a partir do tipo de processo genolexical que lhes deram origem.

A composição por justaposição na construção de nomes próprios é aqui considerada pela perspectiva do encandeamento gráfico (sem espaço) de dois nomes autônomos, portanto, duas formas livres do ponto de vista do sistema onomástico pessoal do português brasileiro: Anabela (786 f.), Anacelia (731 f.), Anacília (64 f.), Anaclara (607 f.), Anacleide (414f.), Anajulia (386f.), Josenilson (8.574 m.), Josenilton (9.558m.), Josemario (1.573 m.), Luciomario (56 m.), Maraísa (5.013 f.), Maranice (55 f.), Maracelia (71f.)

A composição por aglutinação envolve a sobreposição de elementos fônicos que são coincidentes em posição final e inicial do primeiro e segundo nome, respectivamente: Analice (16.354 f.), Analine (1.033 f.), Analva (71 f.), Anamália (37 f.), Anamélia (535f.), Ivanilton (3.384 m.), Juanilton (28 m.), Maralice (498f.), Maraline (256f.). 
Os formativos da margem esquerda se caracterizam pela formação de prenomes que servem a ambos os gêneros (masculino e feminino): Adcarlos (53 m.), Admárcio (27 m.), Admaria (42f.), Edmário (2.022m.), Ednéia (19.470f.), Gilomar (48 m.), Gilmárcio (341 m.) Vanilda (30/489 f.), Vancarlos (128 m.).

Os elementos da margem direita se caracterizam por, em geral, serem responsáveis pela associação do nome a um dos gêneros (masculino e feminino), havendo casos (como os de-van e-mar), em que se prestam a formação de nomes de ambos os gêneros: Carlane (833 .f), Flaviane (15.415 .f), Ivanberg (31 .m), Joseberg (66 .m), Francildo (1.808 .m), Josilma (1.523 .f), Marilma (197 .f), Marilza (28.205 .f), Josemiro (509 m.), Rosemiro (2.445 m.), Carlison (448 .m), Nadson (7.258 .m), Marivan (1.376 .m), Rodivan (7.305 m.), Lucimar (67.004 .f), Julimar (5.135 .m).

Os splinters são quebras não morfêmicas de palavras que passam a atuar como verdadeiros afixos e geram uma série de palavras (GONÇALVES, 2016), ocupando as mesmas posições (margem esquerda ou direita) na construção dos novos itens lexicais. São exemplos de splinters Franci-, que ocorre na margem esquerda e -ilson e -erson que se posicionam na margem direita dos nomes: Francivaldo (10.214 m.), Francileide (4.763 f.), Francineide (18.288 f.), Francinaldo (116 m.), Alailson (2.376 m.), Amailson (235 m.), Deilson (3.460 m.), Genilson (32.822 m.), Jonilson (5.214 m.), Nailson (8.015 m.), Deverson (738 m.), Joerson (64 m.), Cleverson (18.995 .m), Talerson (23.m), Maerson (36.m).

O fenômeno conhecido como cruzamento vocabular, também identificado como palavra-valise e blend, é um processo que origina uma nova palavra a partir da fusão de duas palavras-matrizes. Esse é um dos processos mais frequentes entre as criações vernaculares de itens antroponímicos no Brasil, uma vez que é comum se empregar dois nomes de homenagem a parentes (pai e mãe, mãe e tio(a), pai e irmã(o), avós, avôs etc.). É muito difícil ter certeza de quais nomes estão envolvidos no cruzamento vocabular, por isso, os exemplos aqui destacados vem de casos em que tivemos acesso ao processo de formação: Adilan (Adilson + Ana 186 m.), Edívia (Edson + Olívia 26 f.), Francitonia (Francisc(a) + 
Antônia, 30 f.), Jessicleide (Jéssica + Cleide 199 f.), Julícia (Juliana + Letícia 39 f.), Orlângela (Orlando + Rosângela 22 f.), Valdilane (Valdir + Elane 308 f.).

Como veremos a seguir, os padrões construcionais encontrados nos prenomes aventados como possíveis nomes de brasileiros no cenário póspandemia refletem mecanismos de construção de antropônimos vigentes na nossa língua, ainda que alguns dos processos aqui destacados não tenham sido empregados.

\section{NO SUPOSTO CENÁRIO PÓS-PANDEMIA, AS PROJEÇÕES SOBRE A NOMEAÇÃO DE PESSOAS}

Em abril de 2020, a revista Isto é ${ }^{6}$ publicou uma matéria sobre o registro de crianças com nomes relacionados a pandemia na Índia:

Os pais de um casal de gêmeos, nascidos em meio a pandemia do novo coronavírus, decidiram batizar os filhos de Corona (a menina) e Covid (o menino). O caso ocorreu em Raipur, na Índia. Segundo os pais, a escolha inusitada é para que os filhos se lembrem das dificuldades que superaram para nascerem. As informações são da "Press TrustofIndia".

$[\ldots]$

Os bebês nasceram no dia 27 de março e, segundo os médicos, estão saudáveis e já receberam alta. $\mathrm{O}$ casal confessou que ainda pode mudar de ideia e trocar o nome dos gêmeos, mas por enquanto Corona e Covid serão batizados assim. (ISTOÉ, 03/04/2020)

Também em abril de 2020, o site $G 1^{7}$ deu destaque ao fenômeno que se espalhava por toda a Ásia:

Na Ásia cada vez mais pais dão a seus recém-nascidos um nome com referência ao novo coronavírus, visivelmente indiferentes às consequências de sua escolha a longo prazo. Entre outras variações estão "Corona", "Covid" (doença provocada pelo novo vírus) e "Lockdown" (que em inglês significa confinamento).

Quando Tabesa Hill deu à luz em 13 de abril em Bacolod, nas Filipinas, decidiu que a filha deveria ter um "nome que nos recordasse que escapamos

${ }^{6}$ Disponível em: https://istoe.com.br/gemeos-nascem-durante-pandemia-e-sao-batizados-decorona-e-covid/. Acesso em: 20 out. 2020.

7 Disponível em: https:/g1.globo.com/mundo/noticia/2020/04/29/covid-corona-e-lockdownviram-nomes-de-recem-nascidos-na-asia.ghtml. Acesso em: 20 out. 2020. 
da Covid-19", de acordo com o pai da menina, John Tupas, de 23 anos. Por este motivo, a recém-nascida virou Covid Marie.

Poucas semanas antes, duas mães do sudeste da Índia tiveram a mesma ideia. Algumas pessoas destacaram que a ideia veio de um médico do hospital onde nasceram as crianças. Uma se chama Corona Kumar e a outra Corona Kumari.

"Eu disse que ajudaria a sensibilizar [a população] sobre a doença e a acabar com os preconceitos a respeito. Para minha surpresa, aceitaram", confirmou o médico, S.F. Basha.

Um casal de migrantes do nordeste da Índia, que ficou bloqueado a milhares de quilômetros de sua residência no estado de Rajasthan, optou pelo nome "Lockdown" para seu filho.

"Nós demos o nome Lockdown para recordar todos os problemas que enfrentamos durante este período difícil", explicou o pai da família à imprensa local. (G1, 29/04/2020)

No Brasil, o fenômeno aparece, ao que se tem notícia, apenas como especulação. Encontramos o fenômeno registrado em postagens em redes sociais como Facebook e Twitter, como se pode ver nas imagens a seguir:

Figura 3 - Postagem no twitter_ prenomes1



Fonte: https://twitter.com/antoniotabet/status/1240784795673772033?lang=en. Acesso: em 20 out. 2020 


\section{Em 2030:}

- Mãe, você me deu esse nome porque nasci no meio da epidemia do coronavírus?

- Não diga besteira Alcolgelson, chama a sua irmã Mascarina e vamos almoçar.

Q8) 132

B Curtir
8 comentários 61 compartilhamentos

$\square$ Comentar

$\Leftrightarrow$ Compartilhar

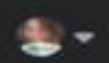

Fonte: https://witter.com/antoniotabet/status/1240784795673772033?lang=en. Acesso: em 20 out. 2020

Figura 5 - Postagem no twitter_prenomes2

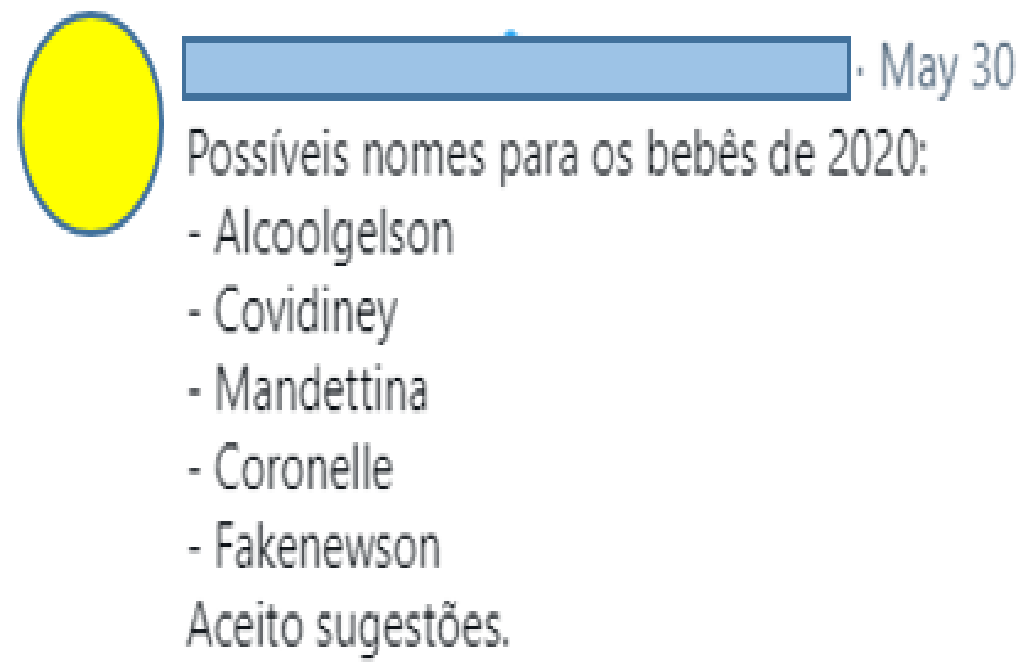

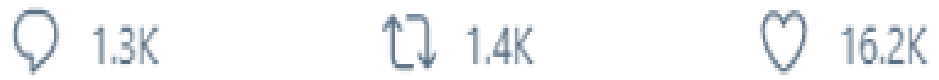

Fonte: https://twitter.com/rafinhabastos/status/1266779729086087170. Acesso em: 20 out. 2020 
As especulações sobre nomes de pessoas, no cenário pós-pandemia, também se apresentaram em vários vídeos no YouTube ${ }^{8}$. Tomando esses dados, conseguimos recolher um total de 38 prenomes aventados como possíveis nomes de brasileiros que apresentam alguma relação com a pandemia de covid-19, a saber:

Tabela 1 - Possíveis prenomes inovadores relacionados à pandemia

\begin{tabular}{|c|c|c|c|}
\hline Alcoolgelson & Corona & Fakenilson & Mascarina \\
\hline Alcolgelza & Coronayara & Fakenewson & Mascarita \\
\hline Alcolgerson & Coronelle & Live/ Laive & Pandemira \\
\hline Alcolinda & Covid/Covide & Liviana & Pandenaldo \\
\hline Alquingel & Covidiana & Liviane & Pandenilde \\
\hline Alquingelson & Covidiane & Lokinilda & Quarentena \\
\hline Anitta & Covidiano & Lokinildo & Quarentenilson \\
\hline Cloroquina & Covidiney & Mandettina & Virusa \\
\hline Coronaldo & Covidson & Maria Cloroquina & \\
\hline Cornardo & Epeilson & Mascaralda & \\
\hline
\end{tabular}

Fonte: elaborado pela autora

https://www.youtube.com/watch?v=SmHNYkSse9Q\&ab_channel=M\%C3\%81RCIODIVULG A\%C3\%87\%C3\%95ES. Acesso em: 20 out. 2020.

Disponível

em:https://www.youtube.com/watch?v=fQnkRzcVxOY\&ab_channel=F\%C3\%A1bricadeaulas . Acesso em: 20 out. 2020.

Disponível

em:https://www.youtube.com/watch?v=TFfLs85BaII\&ab_channel=JeffariaSantosoficial.

Acesso em: 20 out. 2020.

Disponível

https://www.youtube.com/watch?v=_730LmujJVI\&ab_channel=KAU\%C3\%83ZOEIRATV.

Acesso em: 20 out. 2020.

Disponível em: https://www.youtube.com/watch?v=MwNgRaNiMt0\&ab_channel=INCAA. Acesso em: 20 out. 2020.

Disponível

https://www.youtube.com/watch?v=UlpOTvDTNkM\&ab_channel=ChuchuBeleza. Acesso em 20 out. 2020. 
Acerca desse conjunto de nomes, foi feita uma pesquisa ${ }^{9}$ com 100 pessoas de diferentes regiões do país, com idades entre 18 e 69 anos, em que perguntamos se julgavam que cada um dos prenomes poderia ser considerado pouco provável ou muito provável de serem usados no Brasil. O objetivo foi tentar captar a forma como esses prenomes são percebidos a partir da perspectiva dos faltante/receptores.

Os dados indicaram que $98 \%$ dos entrevistados considerou que prenomes como Anitta, Liviana e Liviane são muito prováveis. Isso revela um grande acerto na intuição dos falantes, uma vez que esses prenomes já se encontram em uso no país: Anitta, 41 registros, Liviana, 122 registros e Liviane, 2.027 registros. Considerando que os dados do IBGE apontam registros no país até o ano de 2010, ressaltemos que, nesses casos, é pouco provável que o prenome Anitta tenha relação com o medicamento antiparasitário, assim como é pouco factível que os nomes Liviana e Liviane (provavelmente pronunciados [livi'ãne] e [livi'ãnI]) venham a apresentar qualquer relação com o termo live (do inglês, 'ao vivo'), cuja pronúncia no Brasil se realiza como ['layvI], daí os prenomes inventados serem oralizados nos vídeos com as seguintes pronúncias [layvi'ãne] e [layvi'ãnI],.

Os nomes indicados pelos entrevistados como muito prováveis, em termos percentuais que variam entre 97\% e 70\%, foram: Alcoolgelson, Alcolgerson, Covidiney, Fakenilson e Pandemira. Esses nomes apresentam em comum uma possibilidade de leitura da construção como sendo biformativa, tendo como segundo formativo um prenome já em uso no Brasil: Álcool + Gelson (28.514 registros); Álcool + Gerson (86.856); Covid + Ney (8.287); Fake + Nilson (101.796); Pande(mia) + Mira (1.379). Assim, a possibilidade de que a construção seja lida pela perspectiva biformativa nos parece ser o fator preponderante para aceitação dos possíveis prenomes inovadores.

\footnotetext{
9 A pesquisa foi realizada através da internet, utilizando a plataforma Google Forms. Os entrevistados puderam avaliar cada prenome como pouco ou muito provável. Ao final, havia duas questões abertas: 1) como você avalia esses nomes? e 2) você acredita que algum desses nomes esteja ou possa estar em uso no Brasil?
} 
Os prenomes com maior rejeição, ou seja, que foram apontados como pouco prováveis por mais de $85 \%$ dos entrevistados são: Alquingel, Cloroquina, Covid, Lokinilda, Lokinildo, Mascaralda, Mascarina, Mascarita, Quarentena, Virusa. Talvez a restrição ao uso, nesses casos, se deva a aspectos semânticos dos nomes comuns que se apresentam na margem direita dessas construções. Uma exceção a essa leitura seria o nome Corona que foi considerado muito provável por mais de $57 \%$ dos entrevistados. Nesse caso, chama a atenção o fato de que já existem 43 registros de brasileiros com esse prenome ${ }^{10}$, sendo também um sobrenome em uso no país, embora incomum.

Outro aspecto a se destacar é que, embora Cloroquina tenha sido rejeitado pela maioria dos falantes, 66\% consideraram o nome Maria Cloroquina muito provável. Nesse caso, o uso do prenome Maria como um prenome anteposto a Cloroquina torna a construção mais aceitável.

Os demais prenomes analisados ficaram numa média entre 34\% e 68\% de aceitação. Dentre esses, em geral, os mais aceitos são aqueles que apresentam um formativo recorrente na língua como Coviditana (Covidiana), Coviditane (Covidiane), Covid+son (Covidson), Epe(i)+ Ilson (Epeilson).

Uma vez analisados os dados pela perspectiva de recepção, buscamos olhar os mesmos prenomes desde a perspectiva da emissão, perscrutando o percurso morfolexical que está na base geradora dessas formas inovadoras.

Em princípio percebemos que os falantes recorreram ao processo de transcategorização, fazendo migrar nomes do léxico comum ou próprio (nãopersonativo) para o léxico antroponímico. Esse é o caso de: Anitta, Alquingel ${ }^{11}$,

${ }^{10}$ Como o número de ocorrências do prenome é abaixo de 50, o IBGE não apresenta o gráfico que indicaria a década em que esses registros aconteceram. É possível aventar a possibilidade de que os registros tenham relação com o sobrenome Corona (por exemplo, o ator Lauro Corona), ou com o nome do grupo de eurodance Corona, que fez sucesso no Brasil na década de 1990 com o single The rhythm of the night, ou com produtos cuja marca é Corona (uma cerveja e um aparelho de chuveiro) ou, ainda, que seja uma recuperação da forma latina de coroa (do lat. corona -ae).

${ }^{11}$ No caso de Alquingel chamamos a atenção para o processo de aglutinação da expressão Álcool em gel. 
Cloroquina, Corona, Covid/Covide, Live/Laive, Maria Cloroquina, Quarentena. No entanto, o processo de transcategorização, que aparece de forma categórica nos exemplos do fenômeno na Ásia, no Brasil, não é o mais recorrente, aparecendo em apenas oito dos 38 prenomes. Vale lembrar, além disso, que excetuando Anitta e Maria Cloroquina, todos os outros estão entre os mais rejeitados pelos entrevistados.

Entre os brasileiros, segundo as projeções, seriam privilegiadas construções biformativas, seja com dois formativos livres, seja com uso de formativos presos.

A composição se faz presente em sete construções: Álcool + Gelson (Alcoolgelson); Álcool + Gelza (Alcolgelza); Álcool + Gerson (Alcolgerson); Álcoo(l) + Linda (Alcolinda); Alquin + Gelson (Alquingelson); Covid+Ney (Covidiney); Fake + Nilson (Fakenilson).

Contudo, as construções mais recorrentes são as afixais, em especial as que se utilizam de um formativo (geralmente uma forma presa) na margem direita, representadas em 19 instanciações: Corona + -aldo (Coronaldo), Corona + -ardo (Coronardo); Corona + elle (Coronelle); Covid + ana (Covidiana); Covid + ane (Covidiane); Covid + ano (Covidiano); Covid- + -son (Covidson); Fake new(s)- + son (Fakenewson); Live + ana (Liviana); Live + -ane (Liviane); Loki- + -nilda (Lokinilda); Loki- + -nildo (Lokinildo); Mandetta + -ina (Mandettina); Máscara +-alda (Mascaralda); Máscara + ina (Mascarina); Máscara + -ita (Mascarita); Pande- + -naldo (Pandenaldo); Pande- + Nilde (Pandenilde); Vírus- + -a (Virusa). Não foram encontradas construções com formativos da margem esquerda, por exemplo Ed- ou Franci-.

O cruzamento vocabular, com sobreposição de segmentos fônicos, ocorre nos dois casos a seguir: Corona + Nayara (Coronayara) e Pandemia + Mira (Pandemira).

O splinter -ilson encontra representatividade nas construções: Epei- + -ilson (Epeilson), em cuja margem esquerda estaria a sigla EPI (equipamento de proteção individual) e Quarentena +-ilson (Quarentenilson). 
Portanto, do ponto de vista do emissor, o modelo construcional biformativo se revela em sua total potência dentre as projeções de nomes para os brasileiros.

\section{CONSIDERAÇÕES FINAIS}

O principal objetivo deste estudo foi alcançado quando demonstramos que seja pela perspectiva do emissor, seja pela perspectiva do receptor o padrão construcional de antropônimos no Brasil é essencialmente biformativo, assim como têm demonstrado Rodrigues (2016); Rodrigues e Soledade (2017); Simões Neto e Rodrigues (2017); Simões Neto e Soledade (2018); Rodrigues, Simões Neto e Soledade (2020); Soledade (2018; 2019; 2020). Os dados aqui analisados demonstram que, mesmo quando criamos nomes hipotéticos, fazemos uso de modelos, esquemas construcionais e formativos (em posições claramente estabelecidas) entranhados no sistema antroponímico do português brasileiro.

O diferencial desse estudo, no entanto, é o tratamento de dados que não estão legitimados pelo uso na finalidade a que se prestariam, isto é, como registros de prenomes de pessoas reais no Brasil. Embora sejam instanciações, uma vez que foram emitidas por falantes do português brasileiro, esses prenomes ainda não circulam na esfera da oficialidade dos registros civis, pelo menos, ao que se saiba.

A questão a ser levantada, então, é se serão ou não esses nomes empregados como nomes de pessoas reais no Brasil.

Na pesquisa empreendida com 100 falantes do português brasileiro acerca dos dados analisados, ao final, abrimos o questionário para que comentassem o que achavam desses prenomes e, embora a avaliação fosse muito negativa, no sentido de dizer que são "nomes feios", "nomes ruins", "coisa de gente doida", "nomes que fariam mal as crianças", a grande maioria (76\%) julgou ser possível que esses prenomes estejam em uso ou venham a ser utilizados no Brasil. 
Do ponto de vista construcional, vimos que os prenomes inventados estão de acordo com os padrões vigentes das inovações antroponímicas brasileiras, então, a avaliação negativa desses dados não passa pela forma, mas sim pelo sentido. Caímos, assim, na necessidade de refletir como os sentidos da pandemia poderiam se revelar como um tabu linguístico para a criação de nomes de pessoas.

Guérios (1979) vai nos dizer que a palavra Tabu significa a abstenção ou proibição de pegar, matar, comer, ver, dizer qualquer coisa sagrada. Aquele que comete uma ação que esteja envolvida em um tabu fica sujeito a desgraças, tanto coletiva, numa dimensão social mais ampla, quanto, individual ou familiar. “Assim, existem objetos-tabu, que não devem ser tocados; lugares-tabu, que não devem ser pisados ou apenas de que se não deve avizinhar; ações-tabu, que não devem ser praticadas; e palavras-tabu, que não devem ser proferidas" (GUERIOS, 1979, p. 7 - grifo nosso).

Sobre os tabus linguísticos, Guérios (1979) sugere que incidem sobre eles duas definições, uma própria e outra imprópria. A primeira diz respeito à proibição de se dizer certa palavra a qual se atribui um poder sobrenatural capaz de atrair infelicidade e infortúnio ${ }^{12}$. A segunda diz respeito à proibição de dizer algo que se julgue imoral ou grosseiro.

Assim, o tabu linguístico nada mais é do que modalidade do tabu em geral, ou é um prolongamento dos demais tabus. Se uma pessoa, coisa ou ato é interditado, o nome ou a palavra que se lhes refere, é-o igualmente. No caso dos prenomes no Brasil, os tabus não são explícitos, eles estão declarados pelo não uso. (GUÉRIOS,1979, p. 11)

No português brasileiro, os tabus linguísticos que incidem sobre os nomes de pessoas ainda precisam ser melhor estudados. Sabemos, com base nos dados do IBGE, que nomes como Lúcifer, Diabo, Demônio são interditos, assim como

${ }^{12}$ Vejam aqui que Guérios (1979) cita a palavra "desgraça", mas que nós preferimos substituila por "infortúnio", uma vez que há uma crença, que nos foi passada através da família, de que aquela palavra-tabu atrairia aquilo que ela designa. 
nomes de algumas figuras do folclore brasileiro como Curupira, Boitatá, Saci, embora Iara não seja. Sabemos também, que, no Brasil, embora não seja um tabu, o prenome Jesus (35.774) é bem mais restrito que prenomes como Maria (11.734.129) e José (5.754.529). Já o prenome Deus, com apenas 234 registros, aponta para um alto nível de interdição.

No caso dos dados deste trabalho, trata-se de prenomes que evocam a situação extrema que vivemos com a pandemia. Esses prenomes, para os falantes que os analisaram, acionam frames relacionados a MORTE, DOENÇA, TRISTEZA, PERDA DE FAMILIARES, PERDA DE AMIGOS, FALTA DE LIBERDADE, CONFINAMENTO, SOLIDÃO, DISTANCIAMENTO DE ENTES QUERIDOS, FALTA DE SANIDADE MENTAL ${ }^{13}$, enfim, uma série de associações negativas que, segundo eles, estariam sendo transferidas aos prenomes e, assim, aos indivíduos que os carregam. Encaixados no frame PANDEMIA, esses prenomes, em tese, carregariam em si o tabu que a própria doença emana.

Como estamos falando de dados hipotéticos, só podemos aguardar e ver como o sistema antroponímico do português brasileiro será afetado pela pandemia, pois certamente o será. Uma pesquisa realizada por um site britânico mostrou que durante a pandemia os pais do Reino Unido têm optado por registrar seus filhos com nomes relacionados a virtudes, a heroísmo e à segurança.

No Brasil, pesquisas sobre registros civis, nesse e nos próximos anos, poderão nos revelar qual o grau de interdição que atribuímos ao léxico da pandemia quando aplicado ao sistema onomástico pessoal e quais aspectos sócioculturais foram ressaltados nos processos de escolhas de denominação para as crianças nascidas na pandemia.

${ }^{13}$ Palavras e expressões destacadas das respostas nos questionários. 


\section{REFERÊNCIAS}

BOOIJ, G. Construction Morphology. Oxford: Oxford University Press, 2010.

BOOIJ, G. Inheritance and motivation in Construction Morphology. In: GISBORNE, N.; HIPPISLEY, A. (Ed). Defaults in morphological theory. Oxford: Oxford University Press, 2017. p. 18-39.

BOOIJ, G. Morphology in Construction Grammar. In: HOFFMANN, T., GRAEME, T. The Oxford Handbook of Construction Grammar. Oxford: Oxford University Press, 2012.

CARTIER, E. Noms propres et innovations lexicales. Étude linguistique et statistique à partir de Néoveille. Cahiers de lexicologie, Néologie et nomspropres, Paris, n. 113, p. 203-224, 2018.

DICK, M. V. Memória Paulistana: os antropônimos quinhentistas na Vila de São Paulo do Campo. Revista do Instituto de Estudos Brasileiros, São Paulo, v. 33, p. 112-127, 1992.

DICK, M. V. Os nomes como marcadores ideológicos. Acta Semiótica et linguística. João Pessoa, v. 7, n. 1, p. 97-122, 1998.

GONÇALVES, C. A. V. Atuais tendências em formação de palavras. São Paulo: Contexto, 2016.

GONÇALVES, C. A. V. Usos morfológicos: os processos marginais de formação de palavras em português. Gragoatá, Rio de Janeiro, v. 21, p. 219-242, 2006.

GUÉRIOS, R. F. M. Tabus linguísticos. São Paulo: Nacional, 1979.

SOLEDADE, J; LOPES, M. S.; RODRIGUES, L. S. O legado germânico na antroponímia neológica do português do Brasil. In: Estudos Linguísticos e Filológicos Oferecidos a Ivo Castro. Lisboa: Centro de Linguística da Universidade de Lisboa, 2019, v. 1, p. 1417-1446. Disponível em: https://repositorio.ul.pt/jspui/handle/10451/39619. Acesso em: 20 jul. 2020.

RODRIGUES, L. S. Neologia antroponímica: o que os nomes de origem germânica têm a nos dizer?. 2019. 2 tomos. 665 f. Dissertação. (Mestrado em Letras) Faculdade de Filosofia, Letras e Ciências Humanas, Universidade de São Paulo, São Paulo.

RODRIGUES, L. S. Neologismos antroponímicos com base na utilização de formativos germânicos no Brasil. 2016. 61 f. Trabalho de Conclusão de Curso (Bacharelado em Letras) Instituto de Letras, Universidade Federal da Bahia, Salvador, 2016.

RODRIGUES, L. S.; SOLEDADE, J. Germanismos e a contribuição para a antroponímia brasileira. Revista Hyperion, Salvador, n. 8, p. 75-90, 2016. Disponível em: 
http://www.portalseer.ufba.br/index.php/revistahyperion/article/view/17018/11379. Acesso em: 22 jun. 2020.

SEIDE, M. S. Motivações contemporâneas para a escolha do antropônimo. ENTRELETRAS, Araguaína/TO, v. 4, n. 2, p. 90-101, ago./dez. 2013.

SIMÕES NETO, N. A.; RODRIGUES, L. S. A neologia e os processos genolexicais em antropônimos brasileiros: um breve mapeamento de estudos realizados. Mandinga: revista de estudos linguísticos, [s.l.], v. 1, n. 2, p. 110-127, 2017. Disponível em: http://www.revistas.unilab.edu.br/index.php/mandinga/article/view/33. Acesso em: 28 jul. 2020.

SIMÕES NETO, N. A.; SOLEDADE, J. Nomes masculinos X-son na antroponímia brasileira: uma abordagem morfológica, histórica e construcional. Revista de Estudos da Linguagem, Belo Horizonte, v. 26, p. 1295-1350, 2018.

SOLEDADE, J. A hipótese da prevalência de construções biformativas em processos concatenativos e não concatenativos na formação de antropônimos neológicos no Brasil. Estudos Linguísticos e Literários, Salvador, n. 61, 2018, p. 30-48.

SOLEDADE, J. Origens e estruturação histórica do léxico antroponímico do português brasileiro. Macabéa - Revista Eletrônica do NETLLI, Crato, v. 8, n. 2, 2019, p. 411-452.

SOLEDADE, J. Os brasileiros e seus nomes - Investigações sobre a antroponímia no Brasil. 2020. 292 p. (no prelo).

VAN LANGENDONK, W. Theory and Typology of Proper Names. Berlin/ New York: Mouton de Gruyter, 2007.

Nota do editor:

Artigo submetido para avaliação em: 29 de novembro de 2020.

Aprovado em sistema duplo cego em: 29 de janeiro de 2021. 